\title{
Внешнее финансирование от фонда: так ли это сложно, как кажется?
}

Рассказывает генеральный директор АО «НПП «ЭСТО» В. Б. Разумов

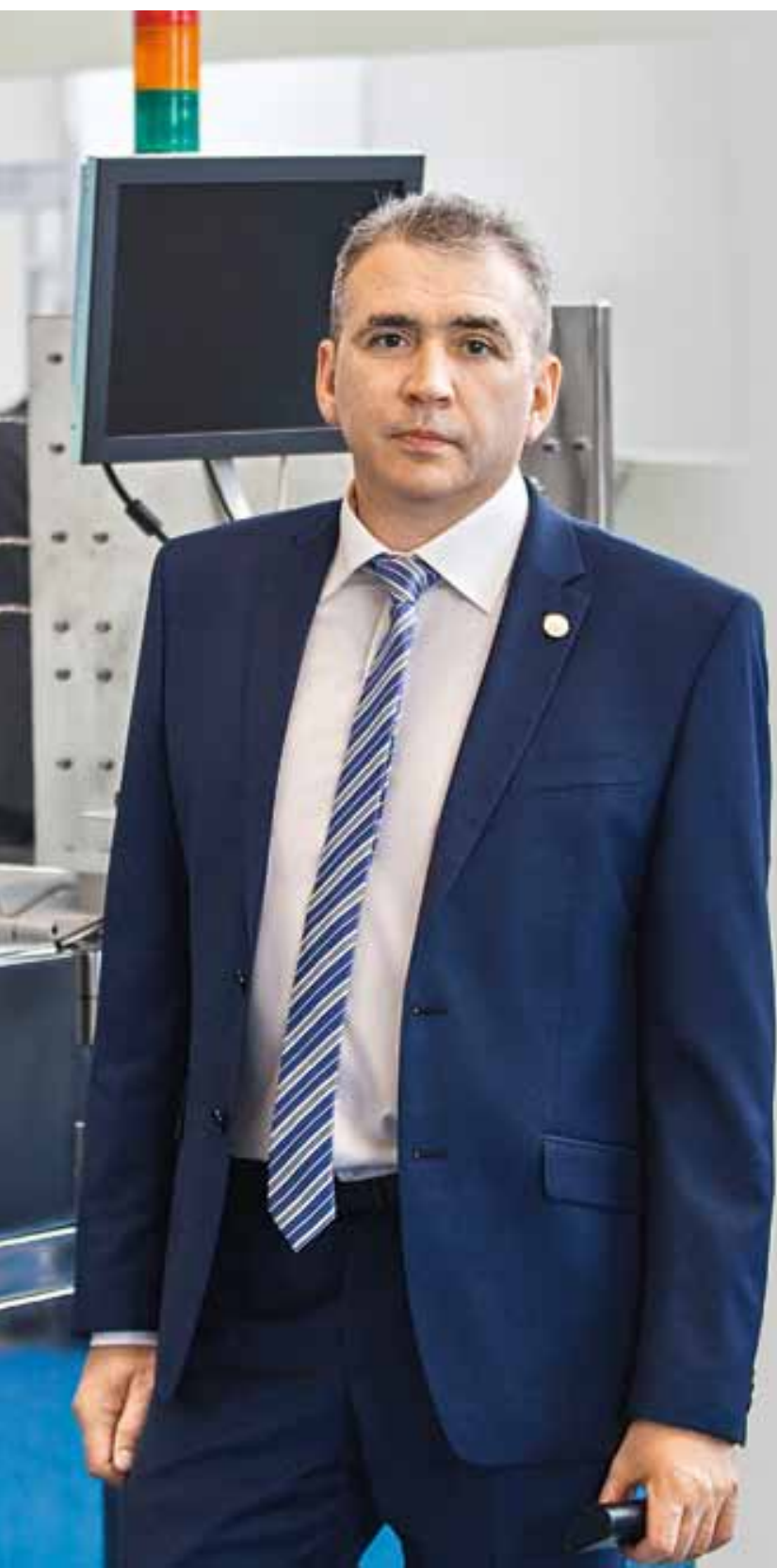

Многие проекты в радиоэлектронной отрасли требуют больших ресурсов, и если малое предприятие берется за такой проект, ему часто необходимо дополнительное финансирование. В России реализуются различные меры поддержки наукоемких и высокотехнологичных разработок, среди которых - услуги фондов. К сожалению, нельзя сказать, что этот инструмент широко используется в нашей отрасли. Однако положительные примеры есть. Наша редакция решила узнать у представителей компаний о причинах, по которым они выбрали этот путь, а такке о том, насколько он был сложен и позволил ли он достичь желаемой цели.

В первом интервью на данную тему Виталий Борисович Разумов, генеральный директор АО «НПП "ЭСТО", рассказал нам историю получения финансирования от Московского фонда поддержки промышленности и предпринимательства. Эта компания, образованная в 2002 году и находящаяся в Зеленограде, специализируется на оборудовании для микроэлектронных производств, при этом не только поставляя предприятиям передовые технологические установки как зарубежного, так и отечественного производства, но и разрабатывая собственное высокотехнологичное оборудование.

За внешним финансированием для завершения одного из таких проектов АО "НПП "ЭСТО" и обратилось в данный фонд.
Виталий Борисович, для чего потребовалось внешнее финансирование?

Внешнее финансирование понадобилось нашей компании для завершения НИОКР и проведения подготовки серийного производства продукции, разработанной нашими конструкторами в рамках реализации госпрограммы импортозамещения.
Проект, по которому осуществляется сотрудничество с фондом, реализуется во взаимодействии с Министерством промышленности и торговли РФ. Его целью является запуск серийного производства технологического оборудования, никогда ранее не производившегося в России - «Технологического модуля (ТМ) критического травления диэлектриков 65-32 нм». Данная разработка 
предназначена для импортозамещения наиболее дорогого и сложного оборудования, применяемого в микроэлектронике и в настоящее время запрещенного к поставкам в России. Оборудование обеспечивает критические технологии плазменного травления глубоких контактов, ячеек памяти, транзисторов и определяет уровень достижимых в стране технологий массового производства микроэлектронной продукции. ТМ предназначен как для массовых, так и для мелкосерийных производств изделий микроэлектроники, в том числе сверхбольших интегральных микросхем, таких как процессоры и память, а также микроэлектромеханических систем (МЭМс) - микродатчиков, гироскопов, акселерометров и т. п.

Какую конечную цель вы планируете достичь в результате выполнения проекта?

Конечной целью проекта является организация отечественного производства линейки передового высокотехнологического плазменного оборудования для предприятий электронной промышленности, позволяющая ликвидировать потенциально опасную зависимость высокотехнологичного сектора страны, в том числе и производств, связанных с ОПК, от иностранных поставщиков оборудования. На данный момент практически всё высокотехнологичное оборудование, имеющееся на предприятиях отрасли - импортное.

Текущая политическая ситуация в мире жестко диктует нам необходимость воссоздания собственного, отечественного производства наиболее критических видов оборудования для этой чувствительной для национальной безопасности отрасли. Ведь любое современное вооружение без специальной электронной компонентной базы превращается просто в груду металла и пластика.

Если отвлечься от глобальных вопросов и вернуться к нашему предприятию, то для нас этот проект очень привлекателен тем, что мы получаем возможность первыми из отечественных производителей закрепиться на достаточно емком рынке, обеспечив наше производство заказами на годы вперед. Общий объем российского рынка для данного оборудования оценивается в 100 млн долл. В год исходя из объемов закупок за последние пять лет. В случае же принятия Государственной программы технического перевооружения российских предприятий микроэлектроники, которая активно обсуждается в Правительстве РФ, предполагается увеличение потребности в данном оборудовании в 2-3 раза.

Как вы узнали о возможности привлечь к финансированию конкретный фонд?

Про Московский фонд поддержки промышленности и предпринимательства мы узнали из публикаций в сети Интернет, в которых рассказывалось о специфике работы фонда с предприятиями сектора высоких технологий и очень привлекательных условиях финансирования, предлагаемых фондом. Так как мы как раз рассматривали разные возможности по привлечению финансирования нашего проекта, это нас очень заинтересовало. Изучив информацию, размещенную на сайте фонда и поняв, что наша компания соответствует требованиям фонда к потенциальным заемщикам, мы связались с его специалистами. С этого началось наше сотрудничество с фондом

Были ли варианты того, в каком качестве использовать возможности фонда, и рассматривали ли вы другие возможности получить необходимую сумму?

Изначально мы всё-таки ориентировались на привлечение банковского финансирования к нашему проекту. Однако очень быстро выяснилось, что коммерческие банки крайне неохотно работают с малыми предприятиями: операционные расходы на анализ бизнеса сопоставимы со средним и крупным бизнесом, а маржа неизмеримо

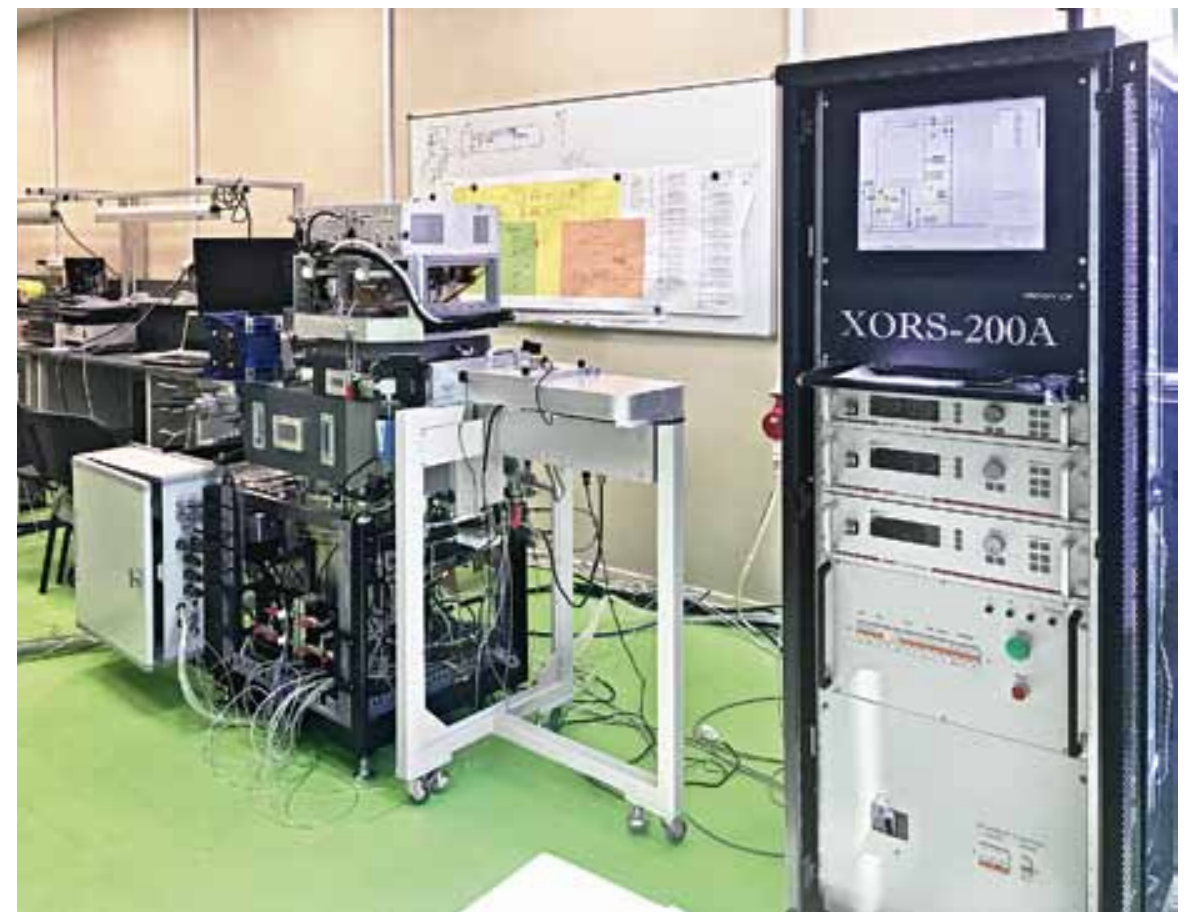

Образец технологического модуля критического травления диэлектриков 
ниже, так как суммы запрашиваемых кредитов относительно невелики. Кроме того, кредиты малому бизнесу считаются высокорисковыми и требуют создания крупных резервов. Выделение же сколько-нибудь серьезного банковского финансирования проектам в высокотехнологичном секторе - вообще уникальное событие. Особенно трудно получить кредит под высокотехнологичный инвестиционный проект на ранних стадиях, до запуска продукции в серийное производство.

Так что получение финансирования со стороны фонда стало на тот момент наиболее реальной возможностью для продолжения реализации проекта.

\section{Были ли трудности при подготовке документов?}

На начальном этапе у нас было несколько предвзятое отношение к возможности сотрудничества с государственными фондами. Были опасения, что всё выльется в долгосрочную бюрократическую волокиту, займет уйму времени и ни к чему в итоге не приведет.

Однако оказалось, что наши опасения сильно преувеличены. Пакеты документов, затребованные фондом для оценки возможности финансирования нашего проекта, по своей наполненности и объему не сильно отличались от пакетов документов, запрашиваемых в банках. Сотрудники фонда не выглядели чиновниками, ищущими малейший формальный повод, чтобы отказать в заявке. Наоборот, активно консультировали по всем вопросам, связанным с подготовкой документов, и оказывали всяческое содействие.

Каких-то серьезных трудностей в подготовке документов у нас не было.

\section{Сколько времени заняла подготовка документов? Их приняли сразу или потребовалась доработка, корректировка?}

Первые наши контакты с фондом начались еще в начале апреля 2018 года. Тогда же мы начали готовить пакет документов для предварительной проверки нашей заявки на предмет возможности открытия финансирования со стороны фонда.

Предварительный пакет документов был достаточно небольшим. Весь процесс его подготовки и направления в фонд занял у нас не более 10 дней с учетом некоторых потребовавшихся доработок. И это при том, что параллельно шла подготовка отчетности за первый квартал 2018 года для ФНС. И примерно через неделю после предоставления предварительного пакета документов в конце апреля 2018 года - мы получили письмо с согласием фонда на дальнейшую работу по нашей заявке. К письму прилагался основной перечень документов, необходимых для комплексной проверки нашей заявки и принятия решения по её итогам о возможности открытия финансирования. Данный пакет документов был гораздо более объемный, но в общем-то не сильно отличался от стандартных перечней документов, запрашиваемых банками при анализе возможности инвестиционного кредитования.

Подача всех документов по основному пакету - по компании-заемщику и по компании-поручителю - с учетом потребовавшихся пояснений и доработок по представленным документам заняло у нас примерно три месяца, и еще около двух недель ушло на оценку нежилой недвижимости, которую мы предоставляли в залог для обеспечения выделяемого займа.

В конце августа 2018 года, после завершения подачи всех документов и получения одобрения со стороны аналитических служб фонда, нас пригласили на заседание Экспертного совета фонда для очной защиты нашей заявки.

Заседание Экспертного совета проходило 31 августа 2018 года. Мы подготовили подробную презентацию нашей компании и проекта, под который запрашивалось финансирование. Защита нашей заявки прошла успешно, мы сумели убедить Экспертный совет в перспективности, глубокой проработанности и финансовой состоятельности нашего проекта.

Далее заявка прошла утверждение в Наблюдательном совете фонда. В его заседании мы уже не участвовали. После получения всех протоколов начался процесс подготовки договора целевого займа и прочих необходимых документов, таких как договоры поручительства, договор ипотеки и проч.

\section{Как скоро вы получили договор?}

Договор целевого займа с фондом мы подписали 28 сентября 2018 года. В соответствии с ним нашей компании выделялось заемное финансирование в размере 50 млн руб. на пять лет под 2\% годовых с отсрочкой на девять месяцев по погашению основного долга. Условия сотрудничества с фондом уникальны для рынка, и нигде мы не смогли бы привлечь финансирование на столь выгодных условиях.

Сумма финансирования распределяется следующим образом: 60\% - на приобретение оборудования; 30\% - на пополнение оборотных средств: закупку комплектующих и заработную плату проектной команде; 10\% - на проведение опытно-конструкторскихи опытно-технологических работ

Также мы обязались обеспечить вложение собственных средств в проект в размере не менее 25 млн руб.

\section{Как скоро фонд перечислил деньги по займу?}

Денежные средства фонд перечислил примерно через месяц после подписания договора займа. Задержка была связана с необходимостью государственной регистрации договора залога (ипотеки) недвижимости. 
Вы должны отчитываться перед фондом о расходовании заемных средств?

Да, естественно отчетность для фонда требуется. Отчитываемся ежеквартально, подтверждая целевое использование выделенных фондом заемных средств, а также подтверждая суммы собственного финансирования, затраченные на реализацию проекта.

Отчетность, в принципе, не слишком сложная и включает в себя два основных документа - ежеквартальный отчет об исполнении финансового плана проекта и расшифровку к данному отчету. Также к отчетным документам прилагаются копии подтверждающих документов - договоры, счета на оплату, платежные поручения, накладные, акты выполненных работ и т.п. Отчетность предоставляется в фонд в срок не позднее 10 рабочих дней с даты окончания отчетного квартала. Отчеты в электронной форме размещаются в личном кабинете на сайте фонда, а оригиналы отчетов вместе с заверенными копиями подтверждающих документов передаются в фонд в бумажной форме.

\section{К какому сроку проект должен быть завершен?}

Данный проект реализуется с 2016 года, а перейти к серийному производству оборудования, разработанного в рамках проекта, предполагается в 2020 году. На текущий момент полностью завершена разработка конструкторской и технологической документации по проекту, изготовлены опытные образцы изделия и завершается программа их тестирования, проводимая совместно с потенциальными заказчиками данного оборудования.

\section{Как будут использоваться результаты?}

Оборудование, произведенное в рамках проекта, предполагается использовать в серийном производстве микросхем. В этом секторе промышленности ключевыми потребителями являются "Микрон», "Ангстрем-Т», НИИСИ РАН, ЗНТЦ и др. Большое количество потенциальных потребителей имеется также в мелкосерийном секторе, в том числе в производстве МЭМС аэрокосмического, медицинского и военного назначений, где могут использоваться упрощенные технологические модули в однокамерном варианте. Таких предприятий в России насчитывается более ста. Данный сегмент потребителей очень важен, так как связан в том числе с выполнением гособоронзаказа и других госпрограмм

\section{Какие у вас ожидания в финансовом плане?}

Реализация данного проекта позволит нашей компании занять весомую часть рынка специального технологического оборудования для радиоэлектронной промышленности. Мы рассчитываем, что серийное производство и поставки заказчикам данного оборудования в различных вариантах исполнения позволят

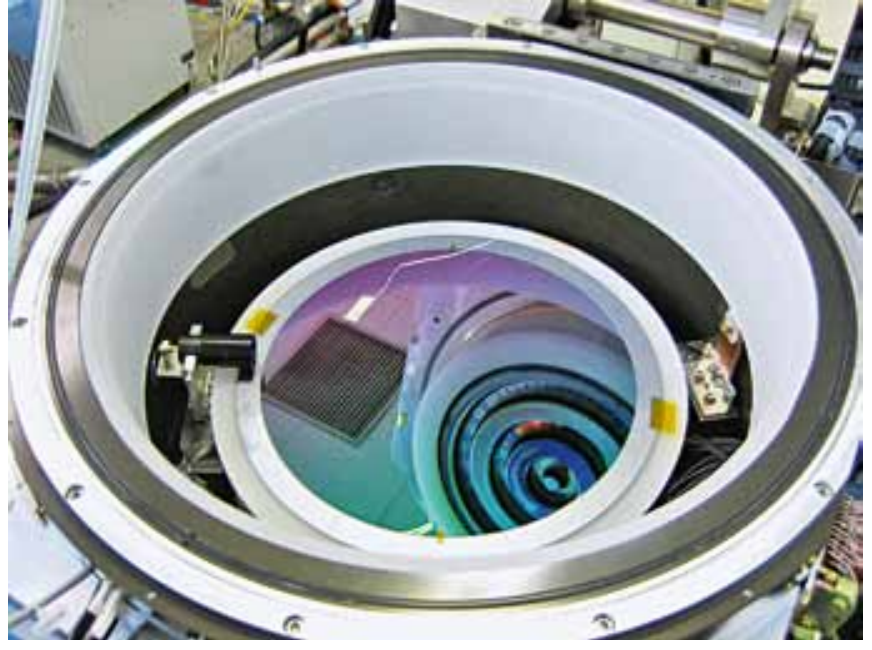

Высокочастотный элемент (антенна) поджига плазмы

нашему предприятию к 2022 году получить выручку 550600 млн руб. в год, в три раза превысив текущий уровень, а к 2025 году преодолеть рубеж в 1 млрд руб. в год.

Какая численность сотрудников была до начала проекта и сколько дополнительных рабочих мест позволит создать его реализация?

До начала проекта - 50 человек. Реализация проекта даст возможность создать дополнительно 20 рабочих мест.

Позволит ли реализация проекта получить преимущества перед конкурентами и какие?

Технологии и ноу-хау, разработанные в рамках реализации проекта, позволят нашему предприятию надолго закрепиться среди лидеров высокотехнологичного машиностроения России. Успешная реализация проекта даст возможность компании начать производство широкой линейки плазменного оборудования на значительно более высоком технологическом уровне, нежели у потенциальных конкурентов в нашей стране. Более того, мы рассчитываем, что оборудование будет вполне конкурентоспособно и по сравнению с зарубежными аналогами.

\section{Будете ли вы обращаться в тот же фонд в дальнейшем?}

Да, мы планируем продолжать наше сотрудничество с фондом. С декабря 2018 года предельная сумма финансирования инвестиционных проектов в промышленность увеличена вдвое - с 50 до 100 млн руб., и у нашей компании появилась реальная возможность привлечь дополнительное финансирование на реализацию своих проектов по разработке и запуску в производство высокотехнологичного отечественного оборудования для предприятий электронной промышленности и смежных отраслей. В настоящее время с фондом ведется активная проработка 
вопросов, связанных с возможным привлечением дополнительного финансирования в рамках его программы поддержки промышленных предприятий Москвы.

\section{Есть ли опыт работы с другими фондами?}

Да, у нашей компании есть большой опыт сотрудничества с Фондом содействия развитию малых форм предприятий в научно-технической сфере (Фонд содействия инновациям), также называемым Фондом Бортника в честь его основателя - Ивана Михайловича Бортника. Наше сотрудничество с этим фондом началось еще 10 лет назад, в 2009 году.

Совместно с Фондом Бортника нами были реализованы такие проекты, как разработка новой универсальной ультразвуковой установки микросварки для микроэлектроники, разработка технологии создания оптических нанокомпозитных материалов и системы нанослоев для лазерных систем с низкими потерями.
Таким образом, наша компания имеет значительный позитивный опыт сотрудничества с Фондом Бортника. Однако работа с этим фондом больше подходит для реализации относительно небольших проектов, так как максимальная величина гранта фонда не превышает 20 млн руб. Этого совершенно недостаточно, когда речь идет о сравнительно крупных проектах, таких как тот, с которым мы обратились в Московский фонд поддержки промышленности и предпринимательства.

Есть ли у вас опыт финансирования проектов физическими лицами (бизнес-ангелами)?

Нет, такого опыта у нас не было. Хотя не исключаю, что в будущих наших проектах такой вариант финансирования будет востребован.

Спасибо за интересный рассказ.

C В. Б. Разумовым беседовала Н. А. стецюк

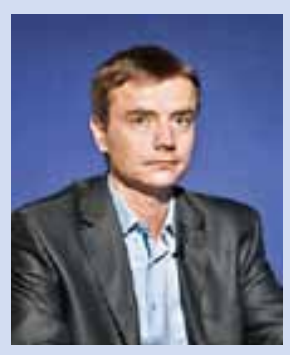

Комментирует генеральный директор Московского фонда поддержки промышленности и предпринимательства Михаил Юрьевич Лопухов

Московский фонд поддержки промышленности и предпринимательства (МФППиП) создан 7 декабря 2012 года на основании Распоряжения правительства Москвы от 13 ноября 2012 года № 695-РП в целях реализации подпрограммы «Москва - город для бизнеса и инноваций» Государственной программы города Москвы «Экономическое развитие и инвестиционная привлекательность города Москвы на 20122018 годы", утвержденной Постановлением правительства Москвы от 11 октября 2011 года № 477-ПП в части развития инфраструктуры поддержки малого и среднего предпринимательства и оказания содействия малым и средним предприятиям в расширении доступа к финансовым ресурсам.

Фонд является подведомственной организацией Департамента инвестиционной и промышленной политики города Москвы. Его целью является финансовая поддержка субъектов промышленности города Москвы, предприятий в сфере научных исследований и разработок, разработчиков программного обеспечения, поддержка московских экспортеров и компаний, которые планируют начать экспортную деятельность. Важной миссией МФППиП также является предоставление льготного долгосрочного финансирования для приобретения отечественного оборудования и улучшения внешнего облика промышленных территорий и объектов капитального строительства промышленных и научных предприятий города Москвы.

Проект, о котором рассказывается в интервью, показателен прежде всего тем, что он иллюстрирует реальную возможность использования внешнего финансирования небольшими компаниями, которые чувствуют в себе силы и обладают высокими компетенциями для создания передовых решений. Именно таким предприятием является АО «НПП «ЭСТО» современный российский производитель сложного технологического оборудования для электронной промышленности; продүкция, разработанная предприятием, уже успешно работает во многих отечественных компаниях.

В интервью идет речь об оборудовании, ранее не производившемся в России, поэтому реализация этого проекта служит не только успеху самой компании, но и решению таких важных для страны задач, как импортозамещение и достижение технологического лидерства. Особенно хотелось бы подчеркнуть тот факт, что проект направлен на запуск разработанного компанией технологического модуля в серийное производство. Иными словами, речь идет не об опытных образцах или прототипах, а о продукции, которую уже в скором времени получит рынок.

За счет займа компания смогла расширить свое техническое оснащение дорогостоящим оборудованием, необходимым для реализации проекта, включая электронный микроскоп, термостабилизаторы, анализатор сети, различные контрольно-измерительные приборы. Виталий Борисович Разумов достаточно подробно рассказал в интервью о том, как происходил процесс получения данного займа, какие были необходимы документы и сколько времени это заняло. Надеемся, что этот рассказ поможет предприятиям, в том числе и из сектора радиоэлектроники, оценить те преимущества, которые предоставляет работа с Московским фондом поддержки промышленности и предпринимательства, и воспользоваться ими для достижения своих амбициозных целей. Связаться с нами можно по телефону +7 495 777-26-96 или электронной почте info@mfppp.ru. Мы будем рады вам помочь!

В заключение хотелось бы пожелать АО «НПП «ЭСТО» и всем российским разработчикам и производителям высокотехнологичных решений успеха в их инновационной деятельности. 